\title{
Editorial: exploring cultural consumption and brands: evolving methods and insights
}

This regular issue once again displays the diversity of research issues, methodologies, and authors in the domain of arts and the market. It comprises a truly international selection of scholars and showcases, in particular, the ever-growing momentum in aspects of audience research and the ongoing interest in arts and cultural consumption.

To set the tone, the issue begins with "Art collecting as consumption and entrepreneurial marketing as strategy" by Ian Fillis and Kim Lehman, which utilizes biographical methods combined with in-depth interviews and participant observation to study the strategy and impact of an art entrepreneur in the context of a privately funded museum in Tasmania, Australia.

Using thematic and metaphor analysis of depth-interviews in Finland, Saara Moiso's article "Expectation of being affected: an enactive perspective of spectators' expectations of contemporary dance" highlights the active and sensory nature of performance. Based on a range of creative methods, Moiso's pioneering work explores audience expectations and interests when attending contemporary dance performances from a range of complementary perspectives and draws out implications for managing audience expectations and engagement.

Steven Hadley is also interested in how audiences' cultural experiences are shaped. In his article "Artists as cultural intermediaries? Remediating practices of production and consumption", Hadley explores the notion of the artist as a cultural intermediary, which he defines as an actor "occupying the conceptual space between production and consumption in an artistic process". Based on interviews with British folk artists, Hadley finds that artists' ability and willingness to engage in processes of intermediation are predominantly determined by their "sense-of-self-as-artist" and shaped by Romantic ideas of artistic autonomy - in this case the belief that artistic production should remain independent from external forces to preserve its aesthetic value.

The audience experience remains in scope as the contribution from Claudia Maria Cacovean, Alessandro Peluso and Ioan Plăiaș again investigates how audiences' experiences can be positively influenced. In their article on consumer satisfaction in Romanian theatres, the authors explore the chain of relationships between service attributes, consumers' perceived benefits, fulfilment of personal goals, satisfaction judgements and future intentions. There are very few quantitative investigations into audience satisfaction in the performing arts, and this study provides a number of fresh insights into how theatres and other cultural venues can enhance audiences' satisfaction, highlighting the vital role of augmented or peripheral services. It also demonstrates how increased satisfaction can drive up loyalty by positively influencing future ticket buying decisions. The study thus develops current knowledge of how consumers think and behave with respect to the performing arts.

The following article, co-authored by Verdiana Chieffi, Marco Pichierri, Alessandro Peluso, Cristiana Collu and Gianluigi Guido, also explores timely questions of marketing and loyalty, but from a very different perspective. "The effect of knowledge type and culture on arts audiences' propensity for experience-sharing" examines the effect of audiences' objective and subjective knowledge (i.e. what they actually know about art and what they think they know) on their propensity to share their arts experiences with other people. Based on a field survey at a large contemporary art museum in Italy and analysed using multiple regression

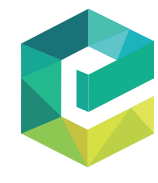

Arts and the Market Vol. 11 No. 3,2021 pp. $169-170$

(c) Emerald Publishing Limited 2056-4945 DOI 10.1108/AAM-10-2021-056 
AAM 11,3

analysis, the study suggests that both subjective and objective knowledge positively affect arts audiences' propensity for experience-sharing. However, the findings indicate that while objective knowledge seems to positively influence experience-sharing when audiences belong to collectivistic cultures, subjective knowledge seems to positively influence experiencesharing when they belong to individualistic cultures. These findings are significant in that they could inform how arts marketers develop their international communication strategies and tailor their engagement to different types of audiences.

David and Helen Waller also engage in audience research to investigate what they refer to as the "heritagisation" of popular culture by museums. Their article reveals how many, predominantly Western, cultural institutions are hosting exhibitions based on popular culture to successfully target new audiences. Their study observes visitors' responses to a specific music-related exhibition, linking intangible and tangible elements of the exhibition to provide a framework to enhance understanding of the audience experience.

In the final article in this issue, "Seeing the invisible: brand authenticity and the cultural production of queer imagination”, Jonatan Södergren and Niklas Vallström shift the reader's focus to the supply side of cultural production. Using visual methods of film criticism and drawing on semiotic analysis of three cult films, the authors outline some of the narrative tensions addressed by filmmakers seeking to offer an authentic voice to queer lives. Challenging Marcuse's warning about the risks of commodification, Södergren and Vallström conclude that queer cinema can sometimes transform market culture and influence positive ideologies regarding gender and sexuality.

This will be the final issue of Arts and the Market that is co-edited by the two of us. After five years as a Co-Editor, Ben is stepping down to focus on his leadership of the Centre for Cultural Value, and we are currently actively recruiting for a replacement Co-Editor. We have greatly enjoyed our tenure as $\mathrm{Co}$-Editors, and although Laurie is staying on as a Co-Editor, we would like to thank all our colleagues at Emerald as well as our Editorial Advisory Board and all of the authors and reviewers we have worked with over the past five years for their combined efforts in strengthening the profile of the journal. In the meantime, we very much hope that you will enjoy this issue and that you're looking forward to our forthcoming special issue on Evaluating Cities of Culture.

Ben Walmsley and Laurie Meamber

\begin{abstract}
About the authors
Ben Walmsley is the Professor of Cultural Engagement at the University of Leeds and Director of the Centre for Cultural Value. Prior to his academic career, he worked as an arts manager for ten years, most recently as a Producer at the National Theatre of Scotland. Since 2014 Ben has been the Academic Director of the Arts Fundraising and Philanthropy Programme, which is now one of Arts Council England's National Portfolio Organisations. Ben is the Co-Editor of Arts and the Market and has published widely on arts marketing, arts management, cultural policy and cultural value. His monograph Audience Engagement in the Performing Arts: A critical analysis was published by Palgrave Macmillan in 2019. Ben is currently leading a national research project investigating the impacts of COVID-19 on the UK's cultural sector.
\end{abstract}

Laurie Meamber is an Associate Professor of Marketing, School of Business, George Mason University. Her research focuses primarily on the intersections of aesthetics, marketing, consumption, and the arts in consumer culture. Her work has appeared in Consumption, Markets and Culture, Journal of Business Research, Marketing Theory, Advances in Consumer Research, among other publications. She is the Co-Editor for Arts and the Market, and serves on the editorial advisory board for Consumption Markets and Culture. At George Mason University, she is affiliated with the Center for Retail Transformation, the Business for a Better World Center, and the Institute for a Sustainable Earth. 